\title{
Process Configuration Plan of Sales and Distribution for Kalinga State University
}

\author{
Mathew Jun P. Mariani
}

Kalinga State University, Philippines

Received: 08 Oct 2020; Received in revised form: 22 Dec 2020; Accepted: 26 Dec 2020; Available online: 31 Dec 2020

(C)2020 The Author(s). Published by Infogain Publication. This is an open access article under the CC BY license

(https://creativecommons.org/licenses/by/4.0/).

\begin{abstract}
Enterprise Resource Planning System is considered a vital organizational tool that integrates various organizational systems and facilitates error-free transactions and production. ERP packages, if chosen correctly, implemented judiciously, and used efficiently, can raise productivity and profits dramatically. The market for ERP systems is very competitive. The SAP SD module is one of the prime ERP modules produced by SAP. SAP Sales and distribution deals with better control of sales and consumer distribution data and processes in companies. It works closely towards functional process work with other SAP modules. Kalinga State University is among the universities that never stop recognizing innovations to develop services for its clientele. With the benefits above of integrating an SD module in a Higher Education Institution, this study was conducted to help the University internalize the possible solutions in achieving the best sales and distribution services that cater to all its constituent needs. Furthermore, an evaluation of the University's sales and distribution conducted suggests that the University needs the implementation of such a module.
\end{abstract}

Keywords - Sales and Distribution, Master Data, Configuration Requirements, SAP Configuration and Implementation, Accelerated SAP, Enterprise Resource Planning.

\section{INTRODUCTION}

Modern business is a complex multi-component system, and one of the primary elements of which is Information and Communication Technology (ICT). Although every enterprise is unique in its financial and economic activities, several problems are common to all enterprises. These include the management of material, financial and human resources, procurement, marketing, and business processes. It is essential to have a fair business process. A business process is a compilation of connected responsibilities that find their end in releasing a client's service or product. Moreover, a business process is also a set of activities and tasks that, once accomplished, shall complete an organization's goal (Malakooti, 2013).

According to Ledlum (2010), an ERP system is an integrated set of programs supporting core organizational activities such as manufacturing, logistics, finance, accounting, sales, marketing, and human resources. Different departments can use an ERP system to share data and knowledge, reduce costs, and improve business processes management. Furthermore, Busanda (2013) claims that organizations regard the ERP system as an essential organizational tool because it incorporates various organizational structures and promotes error-free transactions and development. ERP systems run on various computer hardware and network configurations, typically using a database as an information repository.

Abugabah and Sanzogni (2010) discussed in a study that there were numerous studies on ERP implementation and several related issues such as implementation procedures, business processes, and outcomes. According to their research, the introduction of the ERP in higher education in Australia has resulted in a further layer of change in universities to replace old administrative and management systems with new ones. However, one of the reasons universities have adopted ERP systems is to improve organizational performance and learning services and improve efficiency in the operation. Consequently, to upgrade 
old and obsolete systems with more effective ones, universities started to adopt ERP systems.

Busanda(2013) enumerated various advantages of implementing an ERP system in an organization. These include (a) It allows you to integrate every process of your organization while simultaneously improving the quality of many areas, such areas such as human resources, accounting, and operations; (b) it helps to raise your production volume and to control your costs more efficiently, and this means that you shall be able to control the whole enterprise more efficiently; (c) ERP systems improve the efficiency of information, allowing organizations to provide real-time information to make decisions and reliable predictions for the enterprise.; and, (d) it improves the commercial activity development in the short and long term.

Protiviti (2015) presented common risk areas for ERP projects, including project management and executive sponsorship, lack of communication, and slow decisionmaking among critical stakeholders, including executive management, business process owners, the IT organization, and compliance. One reason for stakeholders' lack of engagement is that an ERP implementation is simply an IT project. Quite often, core business process owners assign responsibilities for managing all aspects of the process, from overseeing system design to go-live, even if they have little or no experience as project managers or understanding of ERP systems.

In terms of business and technical points of view, SAP benefits for universities include campus-wide incorporation into a standard system; improving internal communications; reducing or eliminating manual processes; enhancing strategic decision-making and planning capabilities: developing a self-service environment for students and faculty; enabling administrative systems to be more available; promoting sophisticated systems; analysis for use in decision-making; integrated workflow, industry best practices, and reduced dependence on paper, (Sabauetal, 2011).

The Sales and Distribution module, which the main focus of the study, manages the selling, shipping, and billing of products and services for an organization. It is a part of the Logistics Area in SAP that supports customer activities. The main areas covered by the SD module includes Pre-sales activities, Sales Order Processing, and Shipping Billing (Sasi, 2014).

Furthermore, HEIs have considered SAP SD module adaption to integrate their management system better to manage increasingly complex operations. From decreasing government funding to stakeholders' increasing expectations, universities are currently under pressure to deliver higher quality educational services for lower costs. For these reasons, the SAP SD module can be very appealing to HEIs as a potential route to meeting standards (Frantz, 2012).

Many reasons attract universities to implement the SD module of SAP systems, including global trends, growth in student numbers, competitive education environment, and quality and performance requirements. These require the Higher Education sector to evolve and replace the existing management and administration systems with SD module of SAP systems, which provide many management tools and facilities that guarantee the efficiency and accessibility for all users (Rabaai \& Abugabah 2011)

Kalinga State University is among the universities that never stop recognizing innovations to develop services for its clientele. With the benefits above of integrating an SD module in Higher Education Institutions, the researcher proposes for the configuration of an SAP SD module for the Kalinga State University, which shall enable the University to improve and provide better services to its clientele.

Generally, this study intended to configure processes using SAP ECC 6.0 sales and distribution module for Kalinga State University. Specifically, the study identified the configuration requirements that shall be considered in the sales and distribution and the areas on processes and sales and distribution data; discussed the issues and challenges related to the ERP implementation; and identified the appropriate ICT infrastructure that shall support the ERP implementation.

\section{METHODOLOGY}

\section{Development Methodology}

Before embarking on implementing SAP, one needs to have a well-planned approach and a project-specific methodology to guide every stage of the process (Pillai, 2012). There are numerous project methodologies available to carry out SAP Project implementation. However, the researcher shall utilize Accelerated SAP (ASAP) software development methodology for this study, for it is a comprehensive solution for efficiently implementing and continuously optimizing SAP software.

The goal of ASAP is to help project management design SAP implementation in the most efficient manner possible by effectively optimizing people, time, quality, and other resources. Using the ASAP approach, project 
management includes the blueprint for optimizing and integrating SAP programs in business processes. This solution was created to ensure a successful, cost-effective, and on-time implementation of all project solutions. Developed by SAP (System Applications and Products) to optimize business suites, this framework streamlines the use of methods, tools, accelerators, and templates developed initially for SAP projects.

The ASAP Roadmap divides the implementation process into five phases shown in Figure 1. Recommendations on applying the SAP program and connections to helpful tools and accelerators are provided in the documents held at each stage of the Roadmap framework.

Project Preparation. As an implementation of SAP aims to map the corporate processes to those identified by SAP, the implementation needs to full awareness of the business processes on-board persons. Amongst other aspects, the project planning process helps to identify this team.

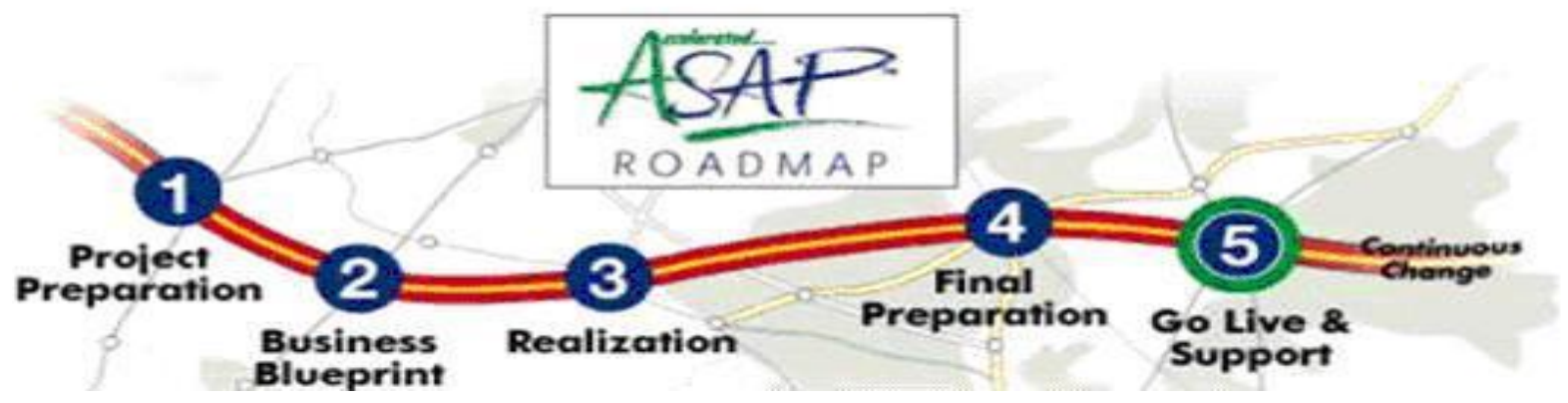

Fig.1: ASAP Roadmap

In this phase, the researcher planned the project and laid the foundations for successful implementation. It is at this stage was the researcher defined strategic decisions needed for this study. This includes defined project goals and objectives, a simplified scope of implementation, and a well-defined project schedule.

Business Blueprint. Blueprint is a comprehensive documentation of the school's requirements, establishing how the business processes and organizational structure are represented in the SAP System. During this phase, the researcher created the AS-Is- and To-Be documents of the organizational structure, processes, and master data.

In this phase, the researcher created a business blueprint and identified the requirements needed. The researcher documented the conceptualized plan through different modeling tools such as swim lane and flow charts that act as the blueprint associated with the study and write all pertinent and analyzed documents.

Realization. The actual work of customizing the SAP software to be in sync with the organization's business processes is done in this phase. It includes customizing existing SAP packages and solutions and developing new objects based on the requirement.

In this phase, the researcher configured the business blueprint requirements using the SAP front end application, the SAP GUI 7.20 version, to access the application accounts.

Baseline configuration follows the final configuration, which consists of up to four cycles. Other key focal areas of this phase conduct integration tests and drawing up end-user documentation.

Final Preparation. Using the improvements from the processes of realization and research, the output method is prepared. Some things need to be performed immediately in the manufacturing system. During the final planning process, these events take place.

In this phase, the researcher completed the preparations, including testing, system management, and cutover activities. At this stage, the researcher ensured all the prerequisites for the system to go live and be fulfilled.

Go-live \& Sustain / Support. The final product is released to the end-users at this point. The go-live can be achieved in a Big Bang (all components at one go or step-byphase fashion ). The project is now progressing into the "sustain and support" phase, where the end-users' concerns will be addressed, and the device will be taken care of for continuous maintenance.

The study does not cover this phase due to the limited available data set needed for the system. Optimizing the system shall not also be covered in this study. 
Sources of Data

The primary source of data in the study's documentation was derived from the researcher's interview with the Business Affairs Officer and the staff. The researcher had created interview guide questions to provide the respondents with a guide in responding to queries. Another data source was the observation of the current Sales and Distribution process, which is being conducted by the sales and distribution staff and clients. Documents were also analyzed to understand the requirements of KSU further. The documents included in this study are the university general ledger, inspection, billing form, product prices, and purchase forms.

\section{RESULTS AND DISCUSSION}

\section{Configuration Requirement for Sales and Distribution Module}

This section discusses the current set-up sales and distribution and the areas of the process, and master data, and the proposed configuration plan of Kalinga State University.

On Process. The processes of selling products at the University are different from that of selling services. This section explains the current process of sales and distribution of KSU followed by the To-be configuration process.

a. Sales of livestock. The University has been producing livestock for 20 years, and it has been one of the most significant income-generating projects of the research and development center. The as-is process in selling livestock is as follows the client must secure first a request for sell form from the Business Affairs (BA) Office of the University. The livestock shall be delivered at the university compound's inspection area for inspection to be headed by the Agricultural Product Income Generating Chairman. If the livestock does not pass the inspection, it shall be returned to the farm. After which, payment is made at the BA offices. An official receipt and a gate pass shall be handed to the clients. The BAO Administrative Aide deposits the collection to BAO accounts at the Land Bank of the Philippines. See appendix C for sell form, Inspection form, and Inspection Report form.

In configuring the to-be process of selling livestock, selling livestock starts when a customer orders, as seen in figure 3. A Sales and distribution staff creates a sales order in the SAP systems using the SAP transaction code VA01. The sales order is filled with customer number, purchase order number, date, delivery plant, material name, price, and quantity of the products the customer wants to buy.

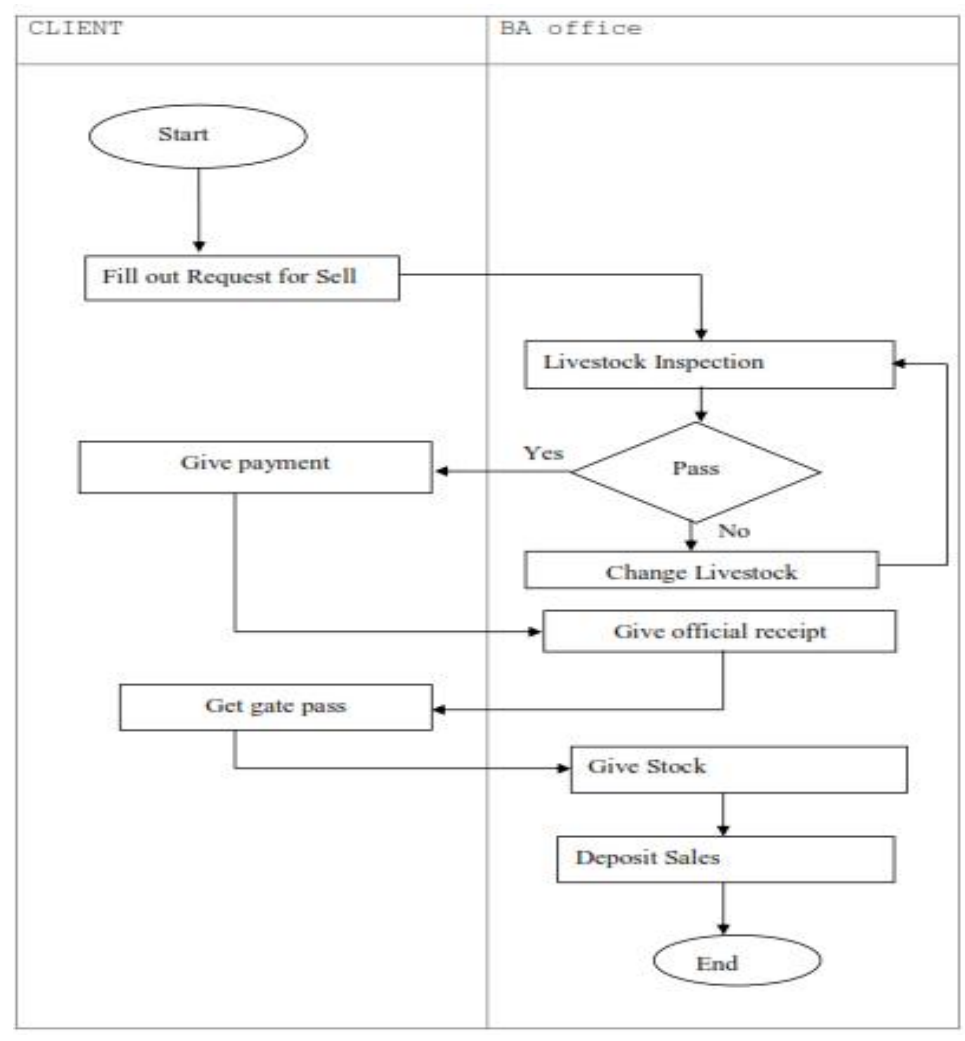

Fig.2: AS-IS Process of Selling Livestock 


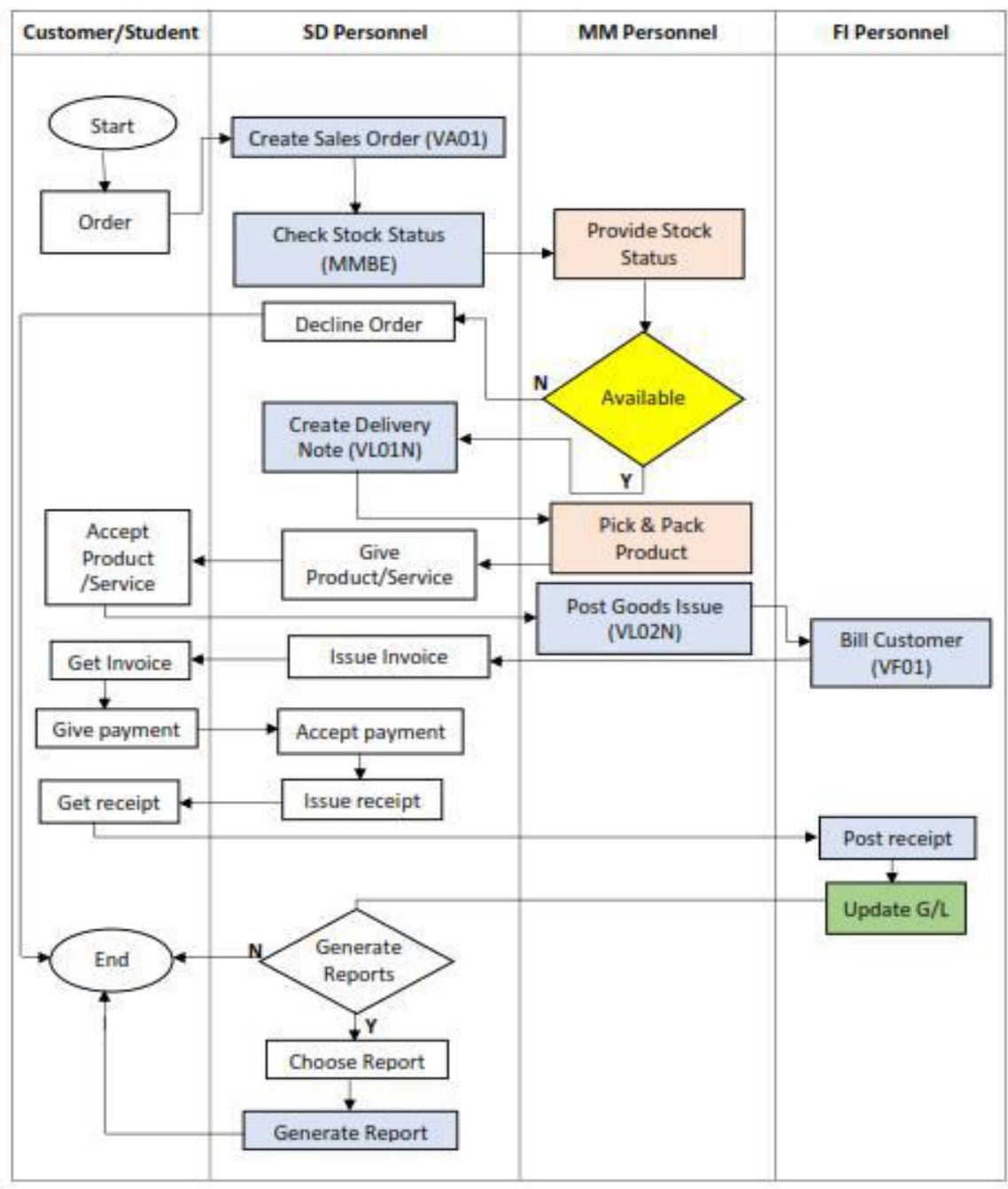

Fig.3: To-be Process of Selling Livestock

c. Dormitory. The University offers male and female dormitories where a faculty is assigned as a dorm matron or patron. Female and male dormitories are located 1 kilometer away from each other.

The as-is process in selling dormitories is as follows: the student must secure a dormitory slot at the Business Affairs Office under the Auxiliary Products and Service office if there is an available bed. The student must initially pay the dorm fee at the cashier's office. After the payment, the student shall be receiving the dorm building and room key.

The to-be process in selling dormitory starts when a customer orders. A Sales and distribution staff creates a sales order in the SAP systems using the SAP transaction code VA01. The sales order is filled with customer number, purchase order number, date, delivery plant, material name, price, and quantity of the products the customer wants to buy. 
International Journal of English Literature and Social Sciences, 5(6)

Nov-Dec 2020 / Available online: https://ijels.com/

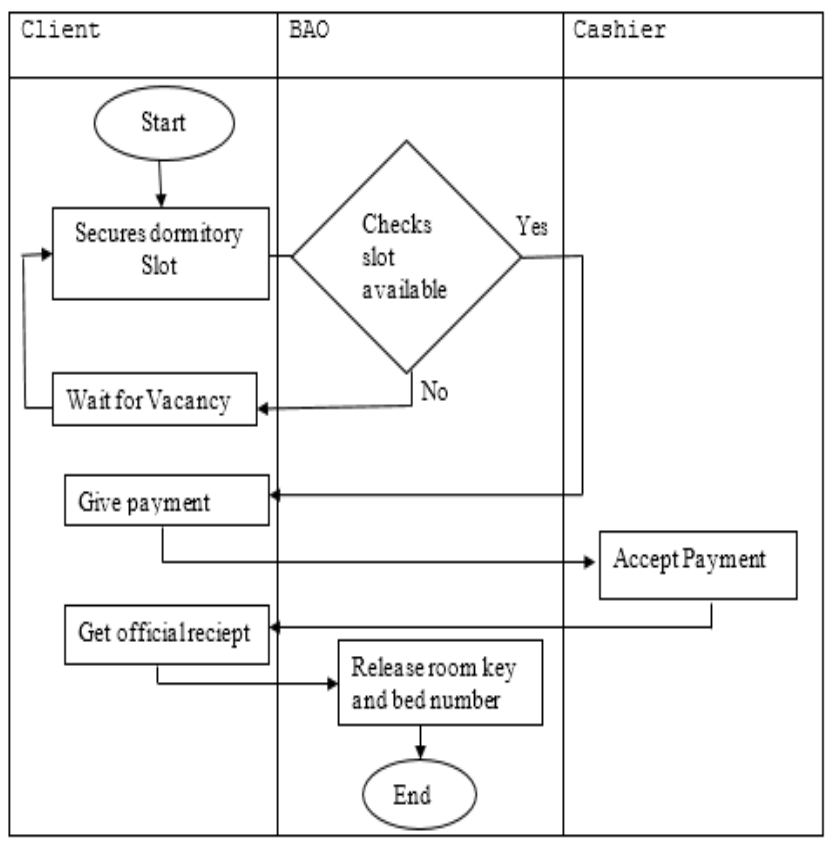

Fig.4: AS-IS Process in Acquiring Dormitory Room

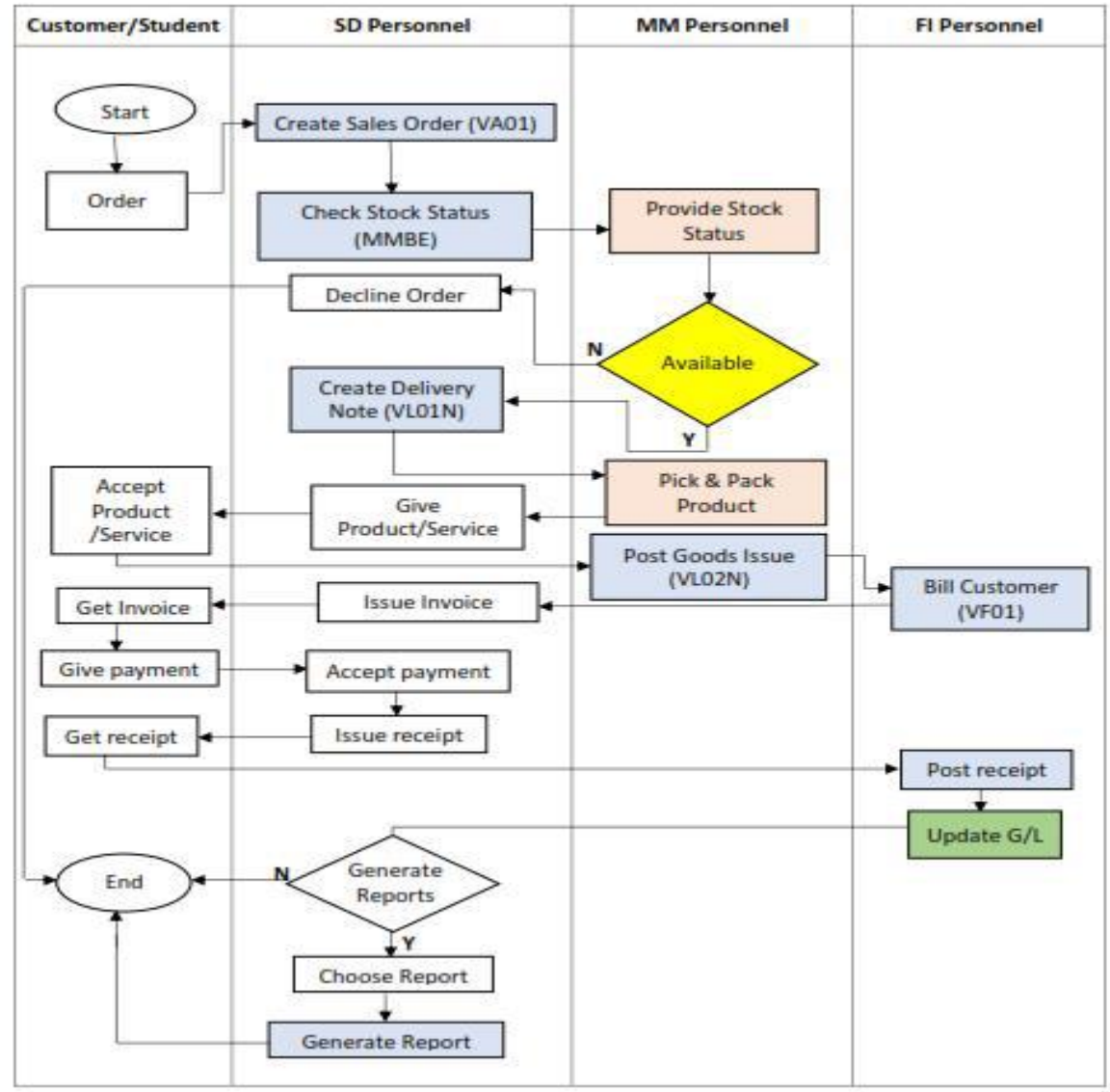

Fig.5: To-be Process of Acquiring Dormitory 
On Master Data. The Master data for SD Module that is used in this study are materials master data, customer master data, and pricing master data.

a. Materials master data. The materials master data are created in the MM module but are extended in the SD module. New views for material masters are created to include the sales view to make the materials available for sale. Materials considered in this paper are dormitory and livestock.

b. Customer master data. Customer master data is the information about the customers that an organization uses to do business with them. Data of client who buys products are created in the system as customers. Information captured in the system includes complete name, address, and contact details. A customer is generated internally by the system upon creation.

\section{Issues and challenges related to ERP implementation}

This section discusses the issues and challenges concerning the implementation of an ERP system in KSU.

Manpower. Change in organizational structure and job descriptions: Employees should undergo a series of training to be familiarized with the ERP SD Module set-up. Some of the employees do not like to undergo a series of training. Moreover, training shall cost the agency much. If not, the other strategy is to hire applicants who have backgrounds in ERP implementation. Another is an unidentified job description sometimes leads to either overlapping or nonassignment of the job description. Another is the equity of employee where in some division needs more manpower than the other division.

Process. Unidentified job leads to procedural protocols that some staff neglect in the process of sales and distribution. For the reason that some protocols were not well established by the office in-charge.

Material. The organization also lack ICT infrastructure, considering the hardware and software requirements in the implementations of ERP. This improvement shall cost the company. Since it is a government-owned and managed agency, budgeting should undergo a series of discussions and consultations, specifically sourcing and aligning budget. Hereto, the justification for such cost should be well organized, and consultation of the different aligned agency should be appropriately considered for budget approval. In this regard, the ERP's full implementation shall take a long and shall depend on the allotted budget by the DMB.

Machine. Problems with the existing equipment include slow processing of computers and slow internet connectivity. Slow processing due to old computer devices and the RAM capacity cannot handle multitasking, and the hard disk is almost full. Some on the computers need to be condemned, reaching the life span of the computers. Slow Internet Connectivity, all the offices use the internet connection, and it reduces the bandwidth.

\section{ICT Infrastructure}

This section discusses the needed ICT infrastructure for the implementation of ERP at KSU. At present, the devices in KSU are not enough for the implementation of SAP.

The ICT Infrastructure for the installation of SAP ERP implements the SAP 3-tier architecture. The three-tier architecture three-tier architecture is Presentation Tier: Occupies the top level and displays information relating to the website's services. By submitting results to the browser and other network levels, this tier interacts with other tiers. Application Tier: This tier is pulled from the presentation tier, called the middle tier, logic tier, business logic, or logic tier. By doing extensive processing, it monitors device functionality. Data Tier: Houses of database servers that store and retrieve information. Data is kept independent of application servers or business logic in this tier.

Software Requirement. The integration of ERP requires the least possible software specification in order for the SAP ECC 6.0 SD Module to run successfully. It is not lower than the company's said software specification to still the software when SAP updates are released. Other application software may be installed, such as office suites and browsers, which are higher than the most recommended.

Table 1 provides the details of the needed software requirements. 
Table 1: Software Requirements

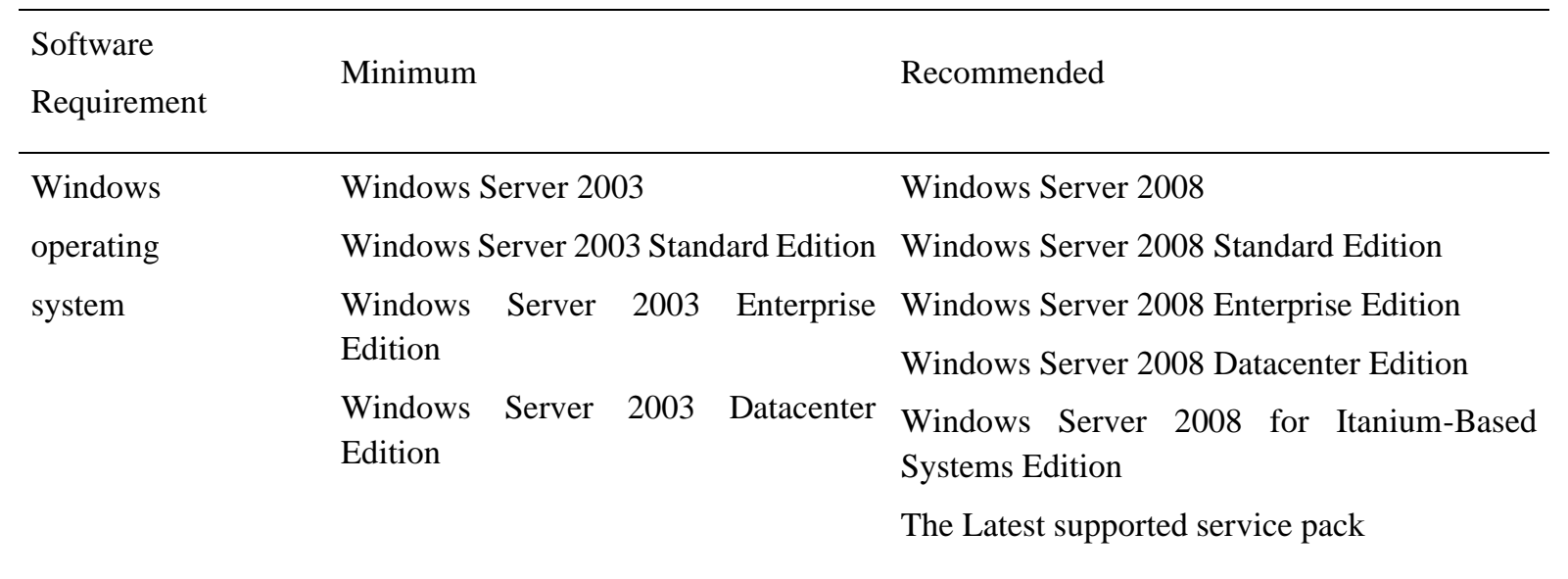

Hardware Requirements. Hardware components in implementing SAP include servers, disk storage systems, and devices to connect to the network like routers, switches, and security firewalls. Back up should also be considered as the availability of a method for the data.

Table 2: Minimum and Recommended Hardware Requirements for the client

\begin{tabular}{lll}
\hline Hardware Component & Minimum & Recommended \\
\hline Processor & Intel/AMD 2.6 GHz processor & 1x intel core i3 \\
RAM & 2 GB RAM & 4 GB RAM \\
Hard Disk & $50 \mathrm{~GB}$ for data And system partition & $\begin{array}{l}100 \mathrm{~GB} \text { for data and system } \\
\text { partition }\end{array}$ \\
Monitor & $1024 \times 768$ with 240bit color or higher & $\begin{array}{l}1024 \times 768 \text { with 240bit color or } \\
\text { higher }\end{array}$ \\
\hline
\end{tabular}

Tables 2 and 3 show the minimum and recommended hardware requirements for the client and server. The company should not go below the recommended requirements for it may cause them problems in the later part due to the upgrade of the software that may demand a higher version of the hardware. These recommended requirements can accommodate updates that are requiring higher hardware specifications.

Table 3: Minimum and Recommended Hardware Requirements for the Server

\begin{tabular}{|c|c|c|}
\hline Hardware Component & Minimum & Recommended \\
\hline Processor & $\begin{array}{l}\text { Intel Processor (or similar) Core } 2 \\
\text { Duo ( } 2.4 \mathrm{GHz} \text { with a } 1066 \mathrm{MHz}) \\
\text { front-side bus or higher }\end{array}$ & $\begin{array}{llll}1 \mathrm{x} \quad \text { Intel Xeon } & \mathrm{E} 3 & \text { (or } \\
\text { equivalent) } & & & \end{array}$ \\
\hline RAM & 4 GB RAM or higher & 8 GB RAM or higher \\
\hline Hard Disk & $250 \mathrm{~GB}$ for data and system partition & $\begin{array}{l}500 \mathrm{~GB} \text { for data and system } \\
\text { partition }\end{array}$ \\
\hline Monitor & $\begin{array}{l}1024 \text { x } 768 \text { with } 240 \text { bit color or } \\
\text { higher }\end{array}$ & $\begin{array}{l}1024 \text { x } 768 \text { with } 240 \text { bit } \\
\text { color or higher }\end{array}$ \\
\hline
\end{tabular}


Network Infrastructure Requirements. The school offices where sales and distribution are performed must have at least three computer units each meeting, the hardware and software minimum requirements to run SAP ECC 6.0. Computers are also required to be installed for the offices that hold material management and financial accounting. These computers are connected to the KSU local area network and shall be provided with an internet connection to access the SAP Server and Database.

Figure 6 shows the proposed network infrastructure for KSU. Computer units shall be connected to the internet for access to the SAP server and database.

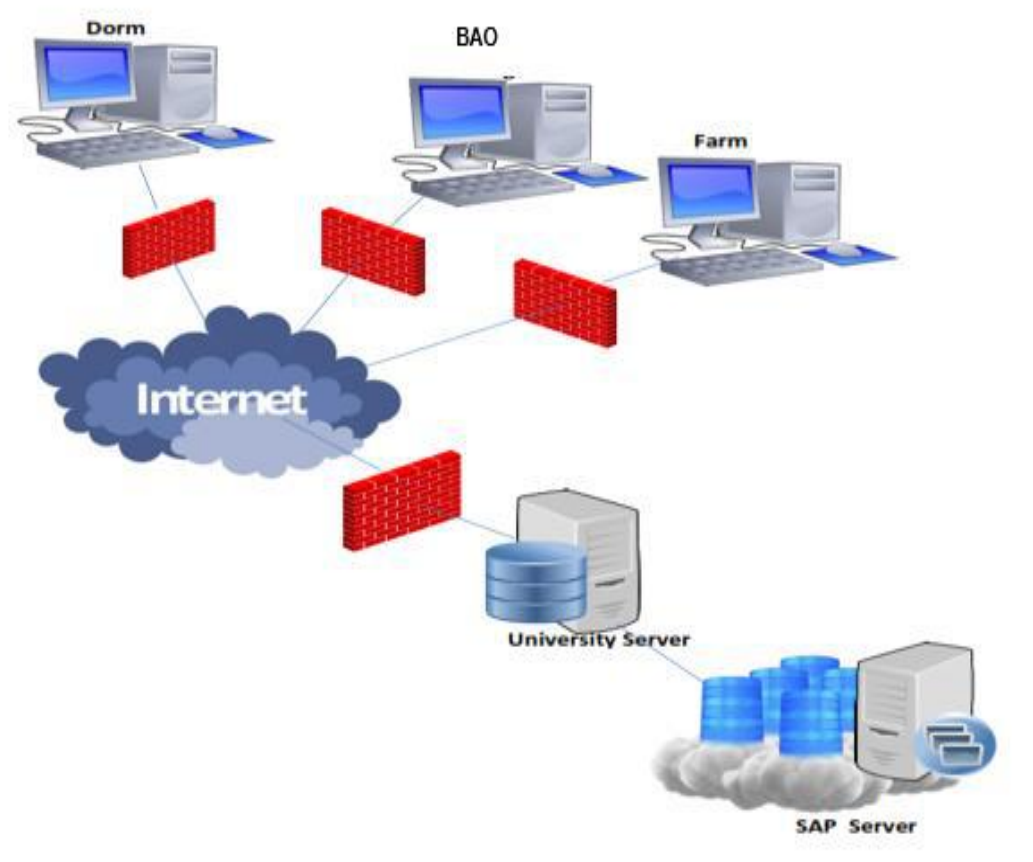

Fig.6: Proposed Network Infrastructure

\section{CONCLUSIONS}

Based on the finding of the study, the following conclusions were derived:

1. The thorough gathering and identification of suited and appropriate configuration requirements revealed that the To-be organization structure created in this study increases working efficiency and decreases administrative cost due to centralized sales and distribution.

As to data needed by the sales and distribution, only the following are required: (a) the management of the personal record of the clients through the customer master data; and (b) the necessity of the material master data, which serves as a list of the livestock \& dormitory as they serve as the products of the University.

2. Issues and challenges cannot be avoided. However, with the help of the process configuration that was done, it will be able to decrease through a thorough study and mapping of organizational structure, process, and master data the corresponding issues and difficulties that were significant in coming up with the ideal To-be adaptions.

3. The sales and Distribution module is appropriate for use in KSU along with the different areas. However, it is also inherent that ICT infrastructure should conform to the minimum hardware and software requirements in the implementation of ERP SAC ECC 6.0. With this, the designed ICT infrastructure will (1) improves the level of coordination between divisions/departments, (2) facilitates the better flow of information, ensuring timely delivery of services, and (3) assures better data management.

\section{RECOMMENDATIONS}

In line with the study's conclusions, since the study covers only the SD module, the researcher highly recommends configuring the needed other modules such as Materials Management, Financial Accounting, Production Planning, Quality Management, and Controlling to obtain its 
full functionality towards achieving organizational goals. Conduct a thorough study on implementing SAP ECC 6.0 in the organization for better role definition within the employees and organizational structure mapping. Enhance the ICT facilities and infrastructure, especially internet connection, security, and purchase of additional equipment and license software, which are needed to implement the SAP configuration successfully. Recommend personnel in Enterprise Resource Planning.

\section{REFERENCES}

[1] Abugabah, A. \& Sanzogni, L. (2010). Enterprise response planning (ERP) System in higher education: A literature Review and Implementation. IJHSS, Volume 5 Issue 6. Retrieved September 07, 2016 from https:/ /www.waset.org/journals.ijhss/v5/v5-6-68.pdf

[2] Adarsh Dhungana, Guaray Kumar, Shantanu Sheth and Sarang Shinde. (February, 2014). Study Of SAP For ERP Applications. IJIRD, Volume 2 Issue 2 ISSN: 2278 - 0211. Retrieved from September 05, 2016 from https:/ www.ijird.com/index.php/ijird/article/download/35015/28212

[3] Aldaba, R. M. (2014). Toward Competitive and Innovative ASEAN SMEs: Philippine SME Policy Index 2012. Makati: NEDA - Philippine Institute for Development Studies.

[4] AlQasham, A. i. (2015). Critical Success Factor (CSF) of Enterprise Resource Planning (ERP) System Implementation in Higer Educations (HEIs): Concept and Literature Review. International Conference on Advanced Information Technologies and Applications (pp. 81-98). Dubai: ICAITA.

[5] Antero, Michelle C, Hedman, Jonas, Henningsson, Stefan. (2011). EVOLUTION OF BUSINESS MODELS: A CASE STUDY OF

SAP. Retrieved September 08, 2016 from http://openarchive.cbs.dk/bitstream/handle/10398/8725/jonas hedman_2.pdf?sequence $=1$.

[6] Bansal, V. (2013). Identifying Critical Success Factors for ERP in SMEs through a Case Study. International Journal of Future Computer and Communication, 1.

[7] Bharathi, S. V. (2012, December6 6). A Study on ERP Adoption in SMEs for Improving Operational Performance and ROI. Retrieved from Social Science Research Network: http://papers.ssrn.com/sol3/papers.cfm?ab stract_id=21862 57

[8] Bhaskar R Nadargi, Prof. C. M. Jadhav. (July, 2015). Ensuring Secured Access to Business Data and Making Industries Trustworthy in the Market via SAP ERP. IJARCSSE, Volume 5 Issue 7 ISSN: 2277 128X. Retrieved September, 03, 2016 from https://www.ijarcsse.com /docs/papers/Volume_5/7.../V5I7-0294.pdf

[9] Deepak Kumar Vishwakarma, K. J. Satao. (July, 2015). Customization of Materials Management Module of SAP ERP for Power Industries of C.G., India. IJARCCE, Volume 4 issue 7 ISSN (Online) 2278-1021 ISSN (Print) 2319-5940.
Retrieved September 07, 2016 from https:/ www.ijarcce.com/upload/2015/july-15/IJARCCE\%2044.pdf

[10] Khor, N. S. (2013, February). Enterprises in the Philippines: Dynamism and Constraints to Employment Growth. Retrieved from www.adb.org: $\underline{\text { http://www.adb.org }}$ /sites/default/files/publication/59604/ewp-334.pdf

[11] Kingsman, M. (2013, February 22). 2013 Research: Compelling Advice for the CFO. Retrieved from ZDNet: http://www. zdnet .com/article/2013-erp-researchcompelling-advice-for-the-cfo/

[12] Klopotek \& Partner GmbH. (November, 2012). JOURNAL SALES AND DISTRIBUTION (JSD) Version 10.8. Retrieved September 07, 2016 from www.klopotek.com/fileadmin /_migrated/.../EN_PS_JSD_108_04.pdf

[13] Leyh, C. (2014). Critical Success Factors for ERP Projects in Small and Medium-sized Enterprises - The Perspective of Selected German SMEs. 2014 Federated Conference on Computer Science and Information System (pp. 118-190). ACSIS.

[14] Manisha Madhwani \& R. Roseline Mary. (April, 2013). An Efficient Framework for Online Dealer Management Portal Using Sap Abap Web-Dynpro. IOSR-JCE, Volume 9 issue 6, e-ISSN: 2278-0661, p- ISSN: 2278-8727. Retrieved September 06, 2016 from iosrjournals.org/ iosrjce/papers/Vol9 Issue6/G0964146.pdf?id=217

[15] Matende, S. a. (2013). Enterprise Resource Planning (ERP) System Implementation: A case for User Participation. CENTERIS 2013 - Conference on ENTERprise Information Systems / PRojMAN 2013 -International Conference on Project MANagement / HCIST 2013 - International Conference on Health and Social Care Information Systems and Technologies (p. 520). Procedia Technology.

[16] Rabaai, A. (2009). The Impact of Organizational Culture on ERP Systems Implementation: Lessons from Jordan. Pacific Asia Conference on Information System (PACIS) (p. 7).

[17] Raj, Aswhin. (n.d.). Role of ERP software in an organization. Retrieved September 06, 2016 from http://www.fibre2fashion.com/industry-article/7/684 /role-oferp-software-in-an-organizational.asp.

[18] Richa Sharma.(September, 2012). ERP - The Changes Trends of Information Technology. IJMIE, Volume 2 Issue 9 ISSN: 2249-0558. Retrieved September 05, 2016 from: www.ijmra.us/project\%20doc/IJMIE.../IJMRA-MIE1587.pdf

[19] SAP. SAP SD Configuration - SAP SALES AND DISTRIBUTION COURSE (With SAP ECC 6.0). Retrieved September 06, 2016 from www.learnsap.com/pdf/sd.pdf

[20] SAP. (2013, January 11). System and Hardware Requirements Guide.

[21] Saxena, Kirti. (2012). Importance of Sales and Distribution Module. Retrieved September 07, 2016 from http://goar ticles .com/articles/Importance-of-Sales-and-Distribu tion/7015456/

[22] Seo, G. (2013, May). Challenges in Implementing Enterprise Resource Planning (ERP) System in Large Organizations: Similarities and Differences Between Corporate and 
University Environment. Cambridge, Massachusetts, United States: MIT.

[23] Sharma, K. \&. (2010). Configuring SAP ERP Sales and Distribution. Indianapolis: Wiley Publishing, inc.

[24] Solution Configurator for SAP Business All-in-One Solution. (n.d.). Retrieved from SAP: https://www.sapconfigurat or.com/sapcfg/build/index.html? lang=en\&campaign=CRMUS08-HUB-TC_FSTWEB\&cntry=us

[25] S. M. Ghosh, H. R. Sharma, V. Mohabay. (August, 2011). Study of Impact Analysis of Software Requirement Change in SAP ERP. IJAST, Volume 33. Retrieved September 07, 2016 from www.sersc.org/journals/IJAST/vol33/9.pd

[26] Naresh Kumer, Pavan Kumar Illa. (June, 2013). Using SAP R/3 for Implementing ERP systems. IJCA, Volume 3 Issue 2, ISSN: 2250-1797. Retrieved September 06, 2016 from www.rspublication.com/ijca/JUNE12/18.pdf

[27] Williams, G. C. (2009). Implementing SAP ERP Sales and Distribution. New York: McGraw-Hill.

[28] Xu, H. R. (2011). Challenge of Implementing an ERP System in Small and Medium Enterprise - Teaching Case of ERP Project Management. Journal of Information System Education, 1-2.

[29] Ziani, Djamal. (2014). CONFIGURATION IN ERP SAAS MULTI-TENANCY. Retrieved September 07, 2016 from https://arx iv.org/ftp/arxiv/papers/1405/1405.0650.pdf

[30] ASAP 8 Methodology for Implementation. (n.d.). Retrieved from SAP - The Best Run Businesses Run SAP - Support Portal: https://support.sap.com/support-programsservices/methodologies/implement-sap/asapimplementation.html

[31] Pillai, K. (2012). ASAP Methodology. Retrieved September 07, 2016 from http://scn.sap.com/community/asapmethodology/blog/2012/03/20/asap-methodlogy.

[32] Waseem, M. (2010). ASAP Methodology. Retrieved September 06, 2016 from http://wiki.sdn.sap./wiki/display/SM /ASAP-Methodology.

[33] What is ERP. Retrieved on August 18, 2016, from https://ww w.syspro.com/us/product/what-is-erp/.

[34] Why SAP Skills are so Important. (2011, August 12). Retrieved on September 30, 2013, from http://www.erp4s tudents.eu/Why-SAP-Skills-are-so-Important_100.aspx.

[35] Zhang, B. (2005). ERP Definition - A Systems Perspective. Retrieved on March 12, 2014, from http://www.sysop tima.com/erp/erp_definition.php. 